\title{
Influence of caffeine on movement characteristics, fertilizing capacity and ability to penetrate cervical mucus of human spermatozoa
}

\author{
R. J. Aitken, F. Best, D. W. Richardson, R. Schats and G. Simm* \\ M.R.C. Reproductive Biology Unit, 37 Chalmers Street, Edinburgh EH3 9EW and *A.R.C. Animal \\ Breeding Research Organization, West Mains Road, Edinburgh EH9 3JQ, U.K.
}

\begin{abstract}
Summary. When added to frozen-thawed human semen, the 3 doses of caffeine tested $(2,5$ and $10 \mathrm{mM})$ induced a significant increase in the percentage of motile spermatozoa but did not influence the quality of movement. Considerable variability was noted between samples in their responsiveness to caffeine which, at the 5 and $10 \mathrm{~mm}$ doses, was significantly correlated with the degree of motility lost during cryostorage. Caffeine treatment of frozen-thawed human spermatozoa also increased the number of spermatozoa penetrating cervical mucus in unit time, by increasing the frequency rather than the success of collisions between spermatozoa and the cervical mucus interface. When caffeine-stimulated spermatozoa were washed free of seminal plasma containing this compound they were no longer at an advantage with respect to their motility or fertilizing ability. When 2 mM-caffeine was added to washed suspensions of capacitated spermatozoa it failed to stimulate motility but did significantly enhance the fertilizing ability of the spermatozoa, indicating a possible clinical role for this compound in in-vitro fertilization therapy.
\end{abstract}

\section{Introduction}

The loss of motility exhibited by human spermatozoa after cryostorage and the concomitant loss of fertilizing potential is a major problem for artificial insemination programmes (Sherman 1964; Serres, Jouannet, Czyglik \& David, 1980; Steinberger, Rodriguez-Rigau \& Smith, 1980). Of the many drugs that have been assessed for their effect on sperm motility (Dott, 1979) the phosphodiesterase inhibitors and, in particular, caffeine have been repeatedly shown to be amongst the most potent (Casillas \& Hoskins, 1970; Garbers, Lust, First \& Lardy, 1971; Burge, 1973; Schoenfeld, Amelar \& Dubin, 1975; Homonnai, Paz, Sofer, Kraicer \& Harell, 1976; Makler, Makler, Itzkovitz \& Brandes, 1980).

The possible use of caffeine to stimulate the motility of cryostored human spermatozoa has been suggested by the positive results obtained by Barkay, Zuckerman, Sklan \& Gordon (1977) and Schill, Pritsch \& Preissler (1979), although caffeine was found to be ineffective in this respect by Read \& Schnieden (1978). Whether caffeine could also affect the ability of cryostored spermatozoa to penetrate cervical mucus and fertilize ova has not been fully explored.

Caffeine might also be used to stimulate the fertilizing ability of washed suspensions of human spermatozoa, to facilitate the use of the in-vitro fertilization/embryo transfer procedure in the treatment of infertility due to poor semen quality. Although appropriate studies have been carried out on the influence of caffeine on the fertilizing ability of guinea-pig (Rogers \& Garcia, 1979) and 
mouse (Fraser, 1979) spermatozoa, no equivalent investigations have been conducted for human gametes.

The purpose of this study was therefore to obtain information relevant to these two potential clinical applications of caffeine.

\section{Materials and Methods}

Donors. The semen samples, obtained from normal healthy donors, contained $>20 \times 10^{6}$ spermatozoa $/ \mathrm{ml}$, had $>40 \%$ motility, $>40 \%$ with normal morphology, and a hamster egg penetration result of $>10 \%$ (Aitken, Best, Richardson, Djahanbakhch \& Lees, 1982).

Cryostorage of spermatozoa. The semen samples were frozen and stored by the techniques described by Jackson \& Richardson (1977). The cryoprotective medium was composed of glycerol $(16 \% \mathrm{v} / \mathrm{v})$, egg yolk $(28 \% \mathrm{v} / \mathrm{v})$, fructose $(1 \cdot 24 \% \mathrm{w} / \mathrm{v})$ and $56 \%(\mathrm{v} / \mathrm{v})$ of a $3 \cdot 2 \%(\mathrm{w} / \mathrm{v})$ stock solution of sodium citrate in distilled water, and was gradually added to the semen at room temperature in 0.5 $\mathrm{ml}$ aliquants until a $1: 1$ dilution was attained. The samples were frozen at an average rate of $7.8^{\circ} \mathrm{C} / \mathrm{min}$ in the vapour phase of a Dewar flask containing liquid nitrogen. After cooling to at least $-120^{\circ} \mathrm{C}$ the samples were rapidly transferred to numbered and colour-coded locations in a sperm storage tank and immersed in liquid nitrogen.

Assessment of movement characteristics. The straws of frozen spermatozoa were thawed out for 5 min at room temperature, followed by $20 \mathrm{~min}$ at $37^{\circ} \mathrm{C}$. The motility of the sample was objectively assessed using an eye-piece graticule and hand-counter. The movement characteristics of the spermatozoa were then measured at $37^{\circ} \mathrm{C}$ under dark-field illumination using time-exposure photomicrography (Overstreet, Katz, Hanson \& Fonseca, 1979; Katz, Overstreet \& Hanson, 1981; Aitken et al., 1982). Four photographs of each sample were taken in rapid succession and the mean velocity of 20 randomly selected tracks was calculated by direct measurement from the photographic prints. These tracks were also analysed to determine the percentage of straight swimming spermatozoa, defined as those spermatozoa exhibiting a progressiveness ratio of 1 (ratio of straight line distance travelled : total distance travelled $=1$ ). The percentage of spermatozoa exhibiting an amplitude of lateral head displacement of $<10 \mu \mathrm{m}$ was also calculated because this characteristic has been shown to exhibit a good correlation with the fertilizing ability of human spermatozoa (Aitken et al., 1982).

Caffeine was dissolved in a balanced salt solution (BWW medium; pH 5.4) based on the description of Biggers, Whitten \& Whittingham (1971) and containing (per litre) $5.54 \mathrm{~g} \mathrm{NaCl}$, $0.356 \mathrm{~g} \mathrm{KCl}, 0.25 \mathrm{~g} \mathrm{CaCl}_{2} .2 \mathrm{H}_{2} \mathrm{O}, 0 \cdot 162 \mathrm{~g} \mathrm{KH}_{2} \mathrm{PO}_{4}, 0.294 \mathrm{~g} \mathrm{MgSO}_{4} .7 \mathrm{H}_{2} \mathrm{O}$ and phenol red; $10 \mu \mathrm{l}$ of this solution were added to $190 \mu \mathrm{l}$ of thawed semen. Control incubations contained $190 \mu$ l of thawed semen and $10 \mu \mathrm{BWW}$ medium without caffeine. The samples were incubated for $20 \mathrm{~min}$ in an atmosphere of $5 \%$ carbon dioxide $: 95 \%$ air and a temperature of $37^{\circ} \mathrm{C}$. The motility of the specimens was then reassessed and sperm movement was re-analysed. The influence of caffeine on the movement characteristics of washed suspensions of capacitated spermatozoa was similarly examined.

Penetration of cervical mucus. Cervical mucus from patients attending an Artificial Insemination by Donor clinic was obtained at mid-cycle by aspiration with a mucus-sampling syringe (Rocket, Watford, England). Samples exhibiting an Insler Score (Insler, Melmed, Eichen Brenner, Serr \& Lunenfeld, 1972) of $>11$ were used within $1.5 \mathrm{~h}$ of collection in a cervical mucus penetration test. The mucus was drawn up into capillary tubes, of rectangular cross-section, exhibiting a depth of $300 \mu \mathrm{m}$ and a volume of $25 \mu \mathrm{l}$ (Camlab, Cambridge, England). One end of the capillary tubes was sealed with 'Parafilm' and the tubes were equilibrated in a humidified chamber for $20 \mathrm{~min}$ at $37^{\circ} \mathrm{C}$ in a gas phase of $5 \%$ carbon dioxide :95\% air. The open end of each capillary tube was then introduced into a $200 \mu \mathrm{l}$ sample of semen which had previously been examined by time-exposure photomicrography to determine the percentage of motile spermatozoa and their total mean 
velocity. After an incubation period of $30 \mathrm{~min}$ the capillary tubes were wiped clean and examined at $\times 100$ under dark-field illumination on the stage of a Leitz Ortholux II microscope to determine the distance of sperm migration. The mucus was then extruded into $475 \mu$ l Dulbecco's phosphatebuffered saline (Flow Laboratories, Irvine, U.K.) containing 0.1\% 2-mercaptoethanol and 10\% formalin. The capillary tube was rinsed repeatedly in this solution and after soaking for $30 \mathrm{~min}$ the concentration of spermatozoa in the cervical mucus was determined from counts obtained with an improved Neubauer haemocytometer.

From a knowledge of the dimensions of the capillary tubes, the duration of incubation, the concentration of spermatozoa in cervical mucus, the concentration of motile spermatozoa in semen and the mean velocity of the motile spermatozoa, a ratio can be calculated which compares the number of successful sperm entries into the mucus with the number of original collisions between the spermatozoa and the cervical mucus/semen interface. This figure is termed the PSC value (Percentage Successful Collisions) and is derived according to the calculations described by Katz et al. (1980).

Hamster egg penetration test. A measure of the fertilizing capacity of human spermatozoa exposed to caffeine was obtained using the zona-free hamster egg penetration test described originally by Yanagimachi, Yanagimachi \& Rogers (1976), as modified by Dor, Rudak \& Aitken (1981), Aitken (1982) and Aitken et al. (1982).

All statistical comparisons were carried out using the paired $t$ test or $\chi^{2}$ analysis.

\section{Results}

\section{Sperm movement characteristics}

The 3 doses of caffeine tested all exerted a significant stimulatory effect on motility (Table 1). Although the degree of stimulation was greatest for the $5 \mathrm{~mm}$ dose $(88 \pm 21 \%)$, considerable variation in responsiveness $(0-261 \%$ increase in motility over the respective control values) was observed between individual samples at all dose levels. At the $5(r=0.536)$ and $10(r=0.80) \mathrm{mm}$ doses, this variability was significantly correlated $(P<0.001)$ with the amount of motility lost as a result of freezing. However, the motility of a sample was not stimulated beyond the value observed before freezing.

Caffeine had a negligible effect on washed suspensions of capacitated spermatozoa in an artificial medium (Table 1). At the $2 \mathrm{~mm}$ dose only 14 out of 26 samples showed any change in motility and in 10 of the 14 stimulated samples the increase in motility over the control value was

Table 1. Influence of caffeine on the motility of human spermatozoa

\begin{tabular}{cccc}
\hline & \multicolumn{3}{c}{$\%$ Motility } \\
\cline { 3 - 4 } $\begin{array}{c}\text { Caffeine } \\
(\mathrm{mM})\end{array}$ & $\begin{array}{c}\text { No. of } \\
\text { samples }\end{array}$ & $\begin{array}{c}\text { Caffeine-free } \\
\text { control }\end{array}$ & Caffeine \\
\hline Frozen-thawed spermatozoa & & \\
2 & 13 & $28 \cdot 3 \pm 3 \cdot 5$ & $44 \cdot 5 \pm 4 \cdot 1^{* * *}$ \\
5 & 15 & $27 \cdot 4 \pm 3 \cdot 9$ & $43 \cdot 0 \pm 3 \cdot 6^{* * *}$ \\
10 & 12 & $30 \cdot 7 \pm 3 \cdot 5$ & $47 \cdot 3 \pm 2 \cdot 9^{* * *}$ \\
\hline Washed, capacitated spermatozoa & \\
2 & 26 & $40 \cdot 3 \pm 4 \cdot 5$ & $41 \cdot 3 \pm 4 \cdot 4$ \\
5 & 23 & $41 \cdot 0 \pm 4 \cdot 2$ & $41 \cdot 2 \pm 4 \cdot 2$ \\
10 & 24 & $42 \cdot 2 \pm 4 \cdot 3$ & $43.9 \pm 4 \cdot 2$ \\
\hline
\end{tabular}


Table 2. Influence of caffeine on the motility of frozenthawed human spermatozoa resuspended in seminal plasma or BWW medium

\begin{tabular}{cccc}
\hline & \multicolumn{2}{c}{$\%$ Motility } \\
\cline { 3 - 4 } $\begin{array}{c}\text { Caffeine } \\
(\mathrm{mM})\end{array}$ & $\begin{array}{c}\text { No. of } \\
\text { samples }\end{array}$ & $\begin{array}{c}\text { BWW } \\
\text { medium }\end{array}$ & $\begin{array}{c}\text { Seminal } \\
\text { plasma }\end{array}$ \\
\hline 2 & 3 & $26.5 \pm 4 \cdot 7$ & $44 \cdot 5 \pm 3 \cdot 3^{*}$ \\
5 & 6 & $25 \cdot 7 \pm 2.5$ & $45 \cdot 7 \pm 3 \cdot 1^{* * *}$ \\
10 & 6 & $23 \cdot 3 \pm 1 \cdot 7$ & $45 \cdot 0 \pm 3.9^{* * *}$ \\
\hline \multicolumn{4}{c}{ Values are mean \pm s.e.m. } \\
& $P<0.01,{ }^{* * *} P<0.001$.
\end{tabular}

Table 3. Influence of caffeine on the velocity of human spermatozoa

\begin{tabular}{|c|c|c|c|}
\hline \multirow[b]{2}{*}{$\begin{array}{l}\text { Caffeine } \\
\text { (mM) }\end{array}$} & \multirow[b]{2}{*}{$\begin{array}{l}\text { No. of } \\
\text { samples }\end{array}$} & \multicolumn{2}{|c|}{ Velocity $(\mu \mathrm{m} / \mathrm{sec})$} \\
\hline & & $\begin{array}{c}\text { Caffeine-free } \\
\text { control }\end{array}$ & Caffeine \\
\hline \multicolumn{4}{|c|}{ Frozen-thawed spermatozoa } \\
\hline 2 & 13 & $19.4 \pm 1.0$ & $17 \cdot 8 \pm 1 \cdot 1$ \\
\hline 5 & 15 & $18.6 \pm 1.0$ & $19 \cdot 1 \pm 1 \cdot 2$ \\
\hline 10 & 12 & $16.5 \pm 1.7$ & $16.1 \pm 0.8$ \\
\hline \multicolumn{4}{|c|}{ Washed, capacitated spermatozoa } \\
\hline 2 & 26 & $25 \cdot 1 \pm 1.5$ & $25 \cdot 4 \pm 1 \cdot 3$ \\
\hline 5 & 23 & $29 \cdot 3 \pm 1 \cdot 3$ & $26.7 \pm 1 \cdot 3$ \\
\hline 10 & 24 & $24.4 \pm 1.2$ & $27.1 \pm 1.5$ \\
\hline
\end{tabular}

$<10 \%$. At the $5 \mathrm{~mm}$ dose, 11 out of 23 samples responded to caffeine with an increase in motility, but in only 2 samples was this response $>10 \%$ over the control value. Similarly at the $10 \mathrm{~mm}$ dose only 6 out of 24 samples exhibited a response to caffeine that represented $>10 \%$ increase over the control value.

As a result of these findings an experiment was designed to control for any mechanical damage inflicted upon the spermatozoa during the centrifugation process involved in the preparation of the washed sperm suspensions and to determine whether the responsiveness of the spermatozoa was related to their state of capacitation. Samples of frozen-thawed human spermatozoa were divided into two aliquots, and centrifuged at $600 \mathrm{~g}$ for $5 \mathrm{~min}$. The sperm pellet was resuspended in BWW medium or seminal plasma. Caffeine was then added to aliquots of the resuspended spermatozoa and the change in \% motility was examined after a 20 min incubation period. The uncapacitated sperm suspensions subjected to a minimum of centrifugation failed to respond to caffeine in an artificial medium, while spermatozoa subjected to an identical centrifugation regimen but resuspended in seminal plasma exhibited full responsiveness (Table 2).

Although a variable proportion of individual semen samples exhibited a response in velocity to caffeine treatment at each dose level, the increase rarely represented more than a $10 \%$ elevation above the control values and the total mean velocities were not significantly changed in the presence of caffeine at any concentration (Table 3). Similarly, no significant changes in the percentage of straight swimming spermatozoa or amplitude of lateral head displacement were detected at any dose of caffeine for frozen-thawed spermatozoa in the cryoprotective medium or washed suspensions of capacitated spermatozoa (data not presented). 
Penetration of cervical mucus

In 14 out of the 15 samples examined, the mean density of spermatozoa in cervical mucus after the $30 \mathrm{~min}$ incubation period was greater in the caffeine-treated samples than in their respective controls (Text-fig. 1a); a result which was significant with respect both to the mean values $(P<$ $0.01)$ and the proportion of samples showing a positive response $\left(\chi^{2}=5.6 ; P<0.02\right)$. No significant changes in PSC values were observed (Text-fig. 1b).
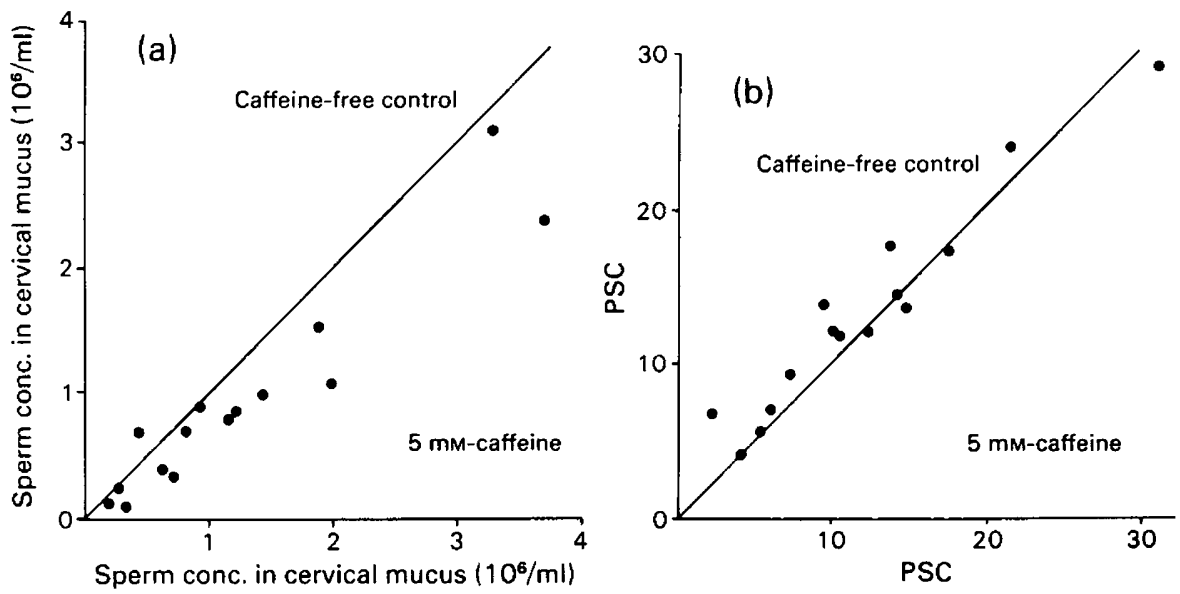

Text-fig. 1. Influence of $5 \mathrm{mM}$-caffeine on (a) the concentration of spermatozoa in cervical mucus and (b) the percentage of successful collisions (PSC value) between spermatozoa and the cervical mucus interface.

\section{Sperm fertilizing ability}

Frozen-thawed semen samples were exposed to caffeine for $20 \mathrm{~min}$, resuspended in BWW medium and then capacitated for $7 \mathrm{~h}$ before being incubated with zona-free hamster ova. The addition of caffeine resulted in a consistent suppression of the fertilizing ability of the spermatozoa, relative to controls exposed to vehicle alone for $20 \mathrm{~min}$ (Table 4). After addition of caffeine to the frozen-thawed semen an increase in motility was observed which was largely lost during the washing procedure and had completely disappeared by the end of the capacitation period when the assessment of fertilizing ability took place (Table 5). Evidently caffeine must remain in contact with the spermatozoa to maintain its influence.

When caffeine was added to the spermatozoa at the end of the capacitation period, at the same time as the zona free hamster ova, and left in contact with the gametes during the $3 \mathrm{~h}$ insemination period, there was a net dose-dependent inhibition of fertilization (Table 6).

Table 4. Effect of caffeine on the fertilizing ability $(\%$ penetration) of human spermatozoa

\begin{tabular}{ccccc}
\hline & & \multicolumn{3}{c}{ Caffeine } \\
\cline { 3 - 5 } Sample & $\begin{array}{c}\text { Caffeine-free } \\
\text { control }\end{array}$ & $2 \mathrm{mM}$ & $5 \mathrm{mM}$ & $10 \mathrm{mM}$ \\
\hline 1 & 34.7 & 31.8 & 5.8 & $2 \cdot 7$ \\
2 & 92.0 & 56.0 & 53.8 & - \\
3 & 96.5 & - & - & 92.0 \\
4 & 25.0 & 17.0 & 20.0 & 10.0 \\
\hline
\end{tabular}


Table 5. Changes in sperm motility* after the addition of caffeine to frozen-thawed human semen and during the subsequent washing and capacitation episodes

\begin{tabular}{|c|c|c|c|c|}
\hline \multirow[b]{2}{*}{ Treatment } & \multicolumn{3}{|c|}{$\%$ Motility } & \multirow[b]{2}{*}{$\begin{array}{c}\text { Penetration } \\
(\%)\end{array}$} \\
\hline & Semen & $\begin{array}{c}\text { After } \\
\text { washing }\end{array}$ & $\begin{array}{c}\text { After } \\
\text { capacitation }\end{array}$ & \\
\hline Control & 46 & 28 & 33 & 25 \\
\hline Caffeine $2 \mathrm{mM}$ & 53 & 32 & 30 & 17 \\
\hline $5 \mathrm{mM}$ & 55 & 32 & 29 & 20 \\
\hline $10 \mathrm{~mm}$ & 64 & 43 & 27 & 10 \\
\hline
\end{tabular}

* Values are for 1 of the 3 experiments covered in Table 4.

Table 6. Influence of caffeine on the fertilizing ability of human spermatozoa when added (a) to the insemination medium and (b) during the last 20 min of the capacitation period

\begin{tabular}{|c|c|c|c|c|}
\hline \multirow[b]{2}{*}{$\begin{array}{l}\text { Caffeine } \\
(\mathrm{mM})\end{array}$} & \multirow[b]{2}{*}{$\begin{array}{l}\text { No. of } \\
\text { samples }\end{array}$} & \multicolumn{2}{|c|}{ Penetration rates $(\%)$} & \multirow{2}{*}{$\begin{array}{c}\text { Net } \% \text { change } \\
\text { in } \\
\text { penetration }\end{array}$} \\
\hline & & $\begin{array}{l}\text { Caffeine-free } \\
\text { control }\end{array}$ & Caffeine & \\
\hline (a) 2 & 7 & $52.4 \pm 11.0$ & $51.4 \pm 11 \cdot 0$ & -0.5 \\
\hline 5 & 7 & $43.7 \pm 10.6$ & $31.3 \pm 8.5^{*}$ & -38.7 \\
\hline 10 & 7 & $59 \cdot 2 \pm 4.9$ & $25 \cdot 1 \pm 4 \cdot 2^{* * *}$ & $-59 \cdot 2$ \\
\hline (b) 2 & 7 & $37 \cdot 6 \pm 10 \cdot 7$ & $47 \cdot 2 \pm 12 \cdot 8^{*}$ & $+20 \cdot 8$ \\
\hline 5 & 5 & $29.1 \pm 13.0$ & $40.1 \pm 13.5$ & -8.8 \\
\hline 10 & 6 & $61.1 \pm 13.1$ & $47.7 \pm 11.9^{* *}$ & -19.8 \\
\hline
\end{tabular}

Values are mean \pm s.e.m.

Compared with control values: ${ }^{*} P<0.05,{ }^{* *} P<0.02,{ }^{* * *} P<0.001$.

To check whether caffeine might exert a toxic effect on the ova, caffeine was added to the sperm suspensions for the last $20 \mathrm{~min}$ of the capacitation period and then removed by centrifugation before introduction of the hamster ova (Table 6). At the $10 \mathrm{~mm}$ dose, caffeine inhibited fertilization with every sample tested $(P<0.02)$. At the $5 \mathrm{~mm}$ dose, stimulation was observed for 2 of the 5 samples examined although the net change in fertilizing capacity for this group was still negative. At the $2 \mathrm{mM}$ dose, however, every sample examined showed an increase in penetration rate in the presence of caffeine $(P<0.05)$.

\section{Discussion}

The present results clearly demonstrate that the motility lost by human spermatozoa during cryostorage can be regained by treatment with caffeine. Relative to the control incubations, caffeine induced $\sim 80 \%$ increase in motility at all dose levels, which is in good accordance with the $81 \%$ increase in motility induced by $5 \mathrm{~mm}$-caffeine in the study of Schill et al. (1979). Barkay et al. (1977) examined the influence of caffeine dose on the increase in motility of cryostored spermatozoa and concluded that $7.2 \mathrm{mM}$ was the optimum concentration for samples stored in excess of 30 days, although the statistical significance of this claim was not calculated. In the present study 5 mMcaffeine gave the highest mean increase in motility $(88 \%)$ although this was not statistically different from the degree of stimulation observed with the 2 and $10 \mathrm{~mm}$ doses. Considerable variation was noted between samples in their responsiveness to caffeine which was, at the 5 and 10 
$\mathrm{mM}$ doses, significantly correlated with the variable amount of motility lost as a result of cryostorage. The addition of $5 \mathrm{~mm}$-caffeine to semen samples that have lost significant motility during cryostorage might therefore be beneficial.

The stimulation of cryostored spermatozoa with caffeine also increased the number of cells entering cervical mucus in unit time. This effect was achieved by increasing the total number of collisions between spermatozoa and the cervical mucus interface and not by increasing the success of these collisions. Whether an increase in the size of the cervical pool of spermatozoa increases the chances of conception in vivo is debatable since this study has also shown that once spermatozoa have lost contact with caffeine they are no longer at an advantage with respect to motility or fertilizing ability. Preliminary experiments in which caffeine was employed as an additive to fresh semen in an Artificial Insemination by Husband clinic tend to support this view (Harrison, 1978) although similar studies with frozen-thawed donor spermatozoa have yet to be carried out.

The influence of caffeine appeared to be confined to an increase in the percentage of motile cells since, within the limits of resolution of time-exposure photomicrography, no significant changes were noted in the mean velocity of the spermatozoa or their patterns of movement. Using similar methods of analysis Haesungcharern \& Chulavatnatol (1973) and Makler et al. (1980) arrived at the same conclusion. Our method and that used by Makler et al. (1980) have been well validated and give highly repeatable objective estimates of the velocity of human spermatozoa. Reports in which an increase in the quality of sperm movement has been observed following caffeine treatment (Schoenfeld et al., 1975; Schill et al., 1979) have used subjective methods for grading the progressiveness of sperm motility and these may be subject to errors of interpretation.

The mechanism by which caffeine stimulates sperm motility is thought to involve the inhibition of phosphodiesterase activity and the subsequent accumulation of cyclic nucleotides, especially cAMP, within the sperm cells (Garbers et al., 1971; Hicks, Martínez-Manautou, Pedron \& Rosado, 1972). The precise way in which elevated intracellular cAMP levels induce an increase in motility is not clearly understood, although the control of calcium ion fluxes across the sperm plasma membrane is probably involved (Peterson, Seyler, Bundman \& Freund, 1979). Greatly elevated levels of intracellular calcium certainly appear to have a detrimental effect on sperm motility (Rosado, Hicks, Martínez-Zedillo, Bondani \& Martínez-Manautou, 1970; Davis, 1978; Peterson et al., 1979; Shams-Borhan \& Harrison, 1981) and cAMP-associated calcium pumps in the plasma membrane appear to be critically important in regulating the content of this ion within the sperm cell (Peterson et al., 1979). Since considerable damage is inflicted on the sperm plasma membrane during cryostorage (Mann \& Lutwak-Mann, 1981) it is possible that the loss of motility observed after freezing and thawing spermatozoa is related to the inability of the damaged plasmalemma to control the levels of calcium within the sperm cell. Caffeine may compensate for this damage and the resultant loss of motility by stimulating the aciivity of an outwardly-directed plasma membrane calcium pump through the mediation of cAMP.

However, in the present study, caffeine could not stimulate the motility of washed suspensions of human spermatozoa before or after capacitation. The most likely explanation for the failure of BWW medium to support caffeine action is the presence of free calcium, since this ion was not present in the Tris-buffered salt solutions employed in previous studies in which caffeine did exert an effect on the motility of washed spermatozoa (e.g. Garbers et al., 1971; Homonnai et al., 1976; Peterson \& Freund, 1976). If phosphodiesterase inhibitors stimulate or maintain sperm motility by removing excess calcium from within the cell (Peterson \& Freund, 1976; Peterson et al., 1979), this effect would be more readily achieved in artificial media lacking calcium since the efflux of this ion would be facilitated by a steep concentration gradient across the sperm plasma membrane.

If this argument is correct, it is surprising that caffeine can stimulate the motility of spermatozoa in semen which contains some $28.2 \pm 3.3 \mathrm{mg}$ calcium $/ 100 \mathrm{ml}$ plasma (Quinn, White \& Wirrick, 1965). However a large proportion of the calcium in semen is either complexed with substances such as citric acid or protein bound. In this respect, there is a specific protein component in bovine seminal plasma that interacts with the sperm surface and decreases the 
permeability of the plasma membrane to calcium (Babcock, Singh \& Lardy, 1979). The antifertilization effects of human seminal plasma (Kanwar, Yanagimachi \& Lopata, 1979) may well depend upon the presence of an analogous substance. Since the success of in-vitro fertilization depends upon the removal of such seminal components and the concomitant exposure of the spermatozoa to free calcium ions to promote both the acrosome reaction (Yanagimachi \& Usui, 1974) and the binding of spermatozoa to the zona pellucida (Saling, Storey \& Wolf, 1978), it is unlikely that phosphodiesterase inhibitors such as caffeine (which may depend on calcium efflux from the sperm cell for their motility-stimulating activity) will ever be effective stimulators of motility in situations designed to promote fertilization.

However, phosphodiesterase inhibitors may still be of clinical relevance for in-vitro fertilization therapy because although caffeine may not stimulate sperm motility in the presence of artificial media the results obtained in this study, and the preliminary report of Rogers (1981), indicate that this compound can enhance the fertilizing ability of human sperm cells. In the present study this enhancement was obtained with a low dose $(2 \mathrm{mM})$ of caffeine and a short exposure time (20 $\mathrm{min}$ ), higher doses proving either occasionally $(5 \mathrm{~mm})$ or consistently $(10 \mathrm{~mm})$ toxic. Although the toxic effects of caffeine on human spermatozoa have been repeatedly demonstrated (Harrison, Sheppard \& Kaliszer, 1980; Traub, Earnshaw, Brannigan \& Thompson, 1982), Rogers (1981) reported an improvement in the fertilizing ability of human spermatozoa when using $7 \mathrm{~mm}$ caffeine and exposure times as long as $6 \mathrm{~h}$, but some methodological details, particularly the procedures used to solubilize the caffeine, were not included. Further studies are clearly required to determine the optimal conditions for exploiting the stimulatory properties of this compound.

This work was supported in part by a grant from the Ruyadh Al-Kharj Hospital, Saudi Arabia, to Professor D. T. Baird, Department of Obstetrics \& Gynaecology, University of Edinburgh.

\section{References}

Aitken, R.J. (1982) The zona-free hamster egg penetration test. In Male Infertility, (in press). Ed. $\mathrm{T}$. Hargreave. Springer-Verlag, Berlin.

Aitken, R.J., Best, F.S.M., Richardson, D.W., Djahanbakhch, O. \& Lees, M.M. (1982) The correlates of fertilizing capacity in normal fertile men. Fert. Steril. $38,68-76$.

Babcock, D.F., Singh, J.P. \& Lardy, H.A. (1979) Alteration of membrane permeability to calcium ions during maturation of bovine spermatozoa. Devl Biol. 69, 85-93.

Barkay, J., Zuckerman, H., Sklan, D. \& Gordon, S. (1977) Effect of caffeine on increasing the motility of frozen human sperm. Fert. Steril. 28, 175-177.

Biggers, J.D., Whitten, W.K. \& Whittingham, D.G. (1971) The culture of mouse embryos in vitro. In Methods in Mammalian Embryology, pp. 86-116. Ed. J. C. Daniel, Jr. Freeman, San Francisco.

Burge, R.G. (1973) Caffeine stimulation of ejaculated human spermatozoa. Urology 1, 371.

Casillas, E.R. \& Hoskins, D.D. (1970) Activation of monkey spermatozoal adenyl cyclase by thyroxine and triiodothyronine. Biochem. Biophys. Res. Commun. 40, 255-262.

Davis, B.K. (1978) Effect of calcium on motility and fertilization by rat spermatozoa in vitro. Proc. Soc. exp. Biol. Med. 157, 54-56.

Dor, J., Rudak, E. \& Aitken, R.J. (1981) Anti-sperm antibodies: their effect on the process of fertilization studied in vitro. Fert. Steril. 35, 535-541.
Dott, H.M. (1979) Spermatozoan motility. Biblphy Reprod. 32, 1-4, 81-84.

Fraser, L.R. (1979) Accelerated mouse sperm penetration in vitro in the presence of caffeine. J. Reprod. Fert. 57, 377-384.

Garbers, D.L., Lust, W.D., First, N.L. \& Lardy, H.A. (1971) Effects of phosphodiesterase inhibitors and cyclic nucleotides on sperm respiration and motility. Biochemistry, N.Y. 10, 1825-1831.

Haesungcharem, A. \& Chulavatnatol, M. (1973) Stimulation of human spermatozoal motility by caffeine. Fert. Steril. 24, 662-665.

Harrison, R.F. (1978) Insemination of husband's semen with and without the addition of caffeine. Fert. Steril. 29, 532-534.

Harrison, R.F., Sheppard, B.L. \& Kaliszer, M. (1980) Observations on the motility, ultrastructure and elemental composition of human spermatozoa incubated with caffeine. Andrologia 12, 34-38.

Hicks, J.J., Martínez-Manautou, J., Pedron, N. \& Rosado, A. (1972) Metabolic changes in human spermatozoa related to capacitation. Fert. Steril. 23, $172-179$.

Homonnai, Z.T., Paz, G., Sofer, A., Kraicer, P.F. \& Harell, A. (1976) Effect of caffeine on the motility, viability, oxygen consumption and glycolytic rate of ejaculated human normokinetic and hypokinetic spermatozoa. Int. J. Fertil. 21, 163-170.

Insler, V., Melmed, H., Eichen Brenner, I., Serr, D.M. \& Lunenfeld, B. (1972) The cervical score. Int. J. Obstet. Gynec. 10, 223-230. 
Jackson, M.C.N. \& Richardson, D.W. (1977) The use of fresh and frozen semen in human artificial insemination. J. biosoc. Sci. 9, 251-262.

Kanwar, K.C., Yanagimachi, R. \& Lopata, A. (1979) Effects of human seminal plasma on fertilizing capacity of human spermatozoa. Fert. Steril. 31, 321327.

Katz, D.F., Overstreet, J.W. \& Hanson, F.W. (1980) A new quantitative test for sperm penetration in cervical mucus. Fert. Steril. 33, 179-186.

Katz, D.F., Overstreet, J.W. \& Hanson, F.W. (1981) Variations within and amongst normal men of movement characteristics of seminal spermatozoa. $J$. Reprod. Fert. 62, 221-228.

Makler, A., Makler, E., Itzkovitz, J. \& Brandes, J.M. (1980) Factors affecting sperm motility. IV. Incubation of human semen with caffeine, kallikrein, and other metabolically active compounds. Fert. Steril. 33, 624-630.

Mann, T. \& Lutwak-Mann, C. (1981) Male Reproductive Function and Semen. Springer-Verlag, Berlin.

Overstreet, J.W., Katz, D.F., Hanson, F.W. \& Fonseca, J.R. (1979) A simple inexpensive method for objective assessment of human sperm movement characteristics. Fert. Steril. 31, 162-172.

Peterson, R.N. \& Freund, M. (1976) Relationship between motility and the transport and binding of divalent cations to the plasma membrane of human spermatozoa. Fert. Steril. 27, 1301-1307.

Peterson, R.N., Seyler, D., Bundman, D. \& Freund, M. (1979) The effect of theophylline and dibutyryl cyclic AMP on the uptake of radioactive calcium and phosphate ions by boar and human spermatozoa. $J$. Reprod. Fert. 55, 385-390.

Quinn, P.J., White, I.G. \& Wirrick, B.R. (1965) Studies of the distribution of the major cations in semen and male accessory secretions. J. Reprod. Fert. 10, 379385.

Read, M.D. \& Schnieden, H. (1978) Effect of two methylxanthine derivatives and four prostaglandins on the motility of spermatozoa from volunteers and oligozoospermic patients. Int. J. Androl. 1, 220-224.

Rogers, B.J. (1981) Factors affecting mammalian in vitro fertilization. In Bioregulators of Reproduction, pp. 459-486. Eds G. Jagiello \& H. J. Vogel. Academic Press, New York.
Rogers, B.J. \& Garcia, L. (1979) Effect of cAMP on acrosome reaction and fertilization. Biol. Reprod. 21, 365-372.

Rosado, A., Hicks, J.J., Martinez-Zedillo, G., Bondani, A. \& Martinez-Manautou, J. (1970) Inhibition of human sperm motility by calcium and zinc ions. Contraception 2, 259-273.

Saling, P.M., Storey, B.T. \& Wolf, D.P. (1978) Calciumdependent binding of mouse epididymal spermatozoa to the zona pellucida. Devl Biol. 65, 515-525.

Schill, W.B., Pritsch, W. \& Preissler, G. (1979) Effect of caffeine and kallikrein on cryo-preserved human spermatozoa. Int. J. Fertil. 24, 27-32.

Schoenfeld, C., Amelar, R.D. \& Dubin, L. (1975) Stimulation of ejaculated human spermatozoa by caffeine. Fert. Steril. 26, 158-161.

Serres, C., Jouannet, P., Czyglik, F. \& David, G. (1980) Effects of freezing on spermatozoa motility. In Human Artificial Insemination and Semen Preservation, pp. 147-160. Eds G. David \& W. S. Price. Plenum Press, New York.

Shams-Borhan, G. \& Harrison, R.A.P. (1981) Production, characterization and use of ionophore-induced, calcium-dependent acrosome reaction in ram spermatozoa. Gamete Res. 4, 407-432.

Sherman, J.K. (1964) Research on frozen human semen. Past, present, and future. Fert. Steril. 15, 485-499.

Steinberger, E., Rodriguez-Rigau, L.J. \& Smith, K.D. (1980) Comparison of results of AID with fresh and frozen semen. In Human Artificial Insemination and Semen Preservation, pp. 283-294. Eds G. David \& W. W. Price. Plenum Press, New York.

Traub, A.I., Earnshaw, J.C., Brannigan, P.D. \& Thompson, W. (1982) A critical assessment of the response to caffeine of human sperm motility. Fert. Steril. 37, $436-437$.

Yanagimachi, R. \& Usui, N. (1974) Calcium dependence of the acrosome reaction and activation of guinea-pig spermatozoa. Expl Cell Res. 89, 161-178.

Yanagimachi, R., Yanagimachi, H. \& Rogers, B.J. (1976) The use of zona-free animal ova as a test system for the assessment of the fertilizing capacity of human spermatozoa. Biol. Reprod. 15, 471-476.

Received 8 February 1982 